\title{
COMPARATIVE STUDY OF THE CLINICAL, LABORATORY AND THERAPEUTIC PROFILE BETWEEN WHITE AND AFRO-DESCENDANTS WITH SYSTEMIC SCLEROSIS AND ASSOCIATED OVERLAY SYNDROMES
}

Luiza Vallory Alochio ${ }^{1, \star}$, Ruben Horst Duque ${ }^{1}$, Valquíria Garcia Dinis ${ }^{1}$, Weider Andrade Tomé1 ${ }^{1}$, Bárbara Ferraço Dalmaso ${ }^{1}$, Raiza Cansian Tuão ${ }^{1}$, Letícia Fonseca Favarato ${ }^{1}$, Thaís Chaves Belisário ${ }^{1}$, Priscila Costa Martins Rocha ${ }^{1}$, Bárbara Fafá ${ }^{1}$, Ketty Lisie Libardi Machado ${ }^{1}$, Débora Marque Veghini1, Gustavo Pinto de Oliveira Gomes ${ }^{1}$, Valéria Valim Cristo ${ }^{1}$

1.Universidade Federal do Espírito Santo, Vitória (ES), Brazil.

${ }^{*}$ Corresponding author: Iualochio@hotmail.com

\section{BACKGROUND}

Ethnicity is an impacting factor in prognosis both in isolated systemic sclerosis (SS) and in SS overlap syndromes (OS-SS). Afro-descendants have more severity and worse prognosis than white people. There are no studies comparing whites and Afrodescendants with SS and OS in Brazil. The present study aims to compare profile of white and Afro-descendant patients with SS and OS-SS followed at the Rheumatology Service of the University Hospital Cassiano Antônio Moraes.

\section{METHODS}

This was a descriptive observational retrospective study. The data obtained was collected from electronic medical record and complemented by telephone interview (when necessary). Inclusion criteria were: patients that met the diagnostic criteria for systemic sclerosis and other connective tissue disease (CTD) associated to SS according to ACR/EULAR for each disease.

\section{RESULTS}

Forty-three patients were included, 24 SS (55.8\%) and 19 OS-SS (44.2\%). In OS-SS, 84.12\% were Afro-descendants, 10.53\% white and $5.25 \%$ had no available data on race. In SS, $62.47 \%$ were Afro-descendants, $20.8 \%$ white and $16.67 \%$ had no available data. General comparative analysis revealed that Afro-descendants had more frequently diffuse SS ( $36.3 \%$ vs. $0, p<0.0001$ ), male gender ( $9 \%$ vs. $0 \%, p<0.0001$ ), cardiac ( $6 \%$ vs. $0, p<0.0001$ ) and renal ( $6 \%$ vs. $0, p<0.0001$ ) involvements and positive anti-Scl-70 $(22.2 \%$ vs. $0 \%, p<0.0001)$ in relation to whites. Whites had higher smoking ( $50 \%$ vs. $18.1 \%, p=0.03)$ and clinical manifestation of gastropathy ( $50 \%$ vs. $21.1 \%, p=0.0496)$. In the laboratory, Afro-descendants had more positive anti-Scl-70 (22.2\% vs. $0 \%$, $p<0.0001)$; while whites more anti-LA (14.2\% vs. $0 \%, p<0.0001)$ and anti-Jo-1 $(12.5 \%$ vs. $0 \%, p<0.0001)$. In the induction treatment for interstitial lung disease (IPD), we observed greater use of mycophenolate in Afro-descendants ( $3 \%$ vs. $0 \%, p<0.0001$ ) and azathioprine in whites $(12.1 \%$ vs. $0 \%, p<0.0001)$. At maintenance, Afro-descendants received more rituximab $(3 \%$ vs. $0 \%$ in whites, $p<0.0001)$. Comparing Afro-descendants in the SS versus OS-SS groups, were observed in SS older age $(51.9+14.98$ vs. $40.6+10.2, p=0.0197)$ and male ( $20 \%$ vs. $0, p<0.001)$, higher exposure to pesticides ( $20 \%$ vs. $0 \%, p<0.001)$ and silica ( $6.6 \%$ vs. $0 \%$, $\mathrm{p}<0.001$ ). As for the manifestations, SS had more calcinosis ( $6.6 \%$ vs. $0 \%, p<0.001$ ), while in OS-SS more neurological involvement $(12.5 \%$ vs. $0 \%, p<0.001)$. In the laboratory, SS had higher positivity for anti-Scl-70 ( $42.8 \%$ vs. $0 \%, p<0.0001)$ and anticentromere (15.38\% vs. $0 \%, p<0.0001$ ); while in OS-SS there was more anti-RNP (66.6\% vs. $20 \%, p=0.0286$ ), anti-SM ( $40 \%$ vs. $0 \%, p<0.0001$ ) and anti-dsDNA ( $33.3 \%$ vs. $0 \%, p<0.0001)$. Mycophenolate was most used in the induction treatment for ILD in Afro-descendants in the OS-SS (6.2\% in OS vs. $0 \%, p<0.0001)$ and rituximab as maintenance therapy for ILD in SS ( $6.6 \%$ vs. $0 \%, p<0.0001)$.

\section{CONCLUSION}

Afro-descendants have more common prognostic factors compared to whites, reinforcing more severe disease and higher mortality in this ethnic group. In Afro-descendants of SS and OS-SS there was no difference that determine impact on survival.

\section{KEYWORDS}

Systemic sclerosis, Overlap syndromes, Afro-descendants. 